\title{
Paulo Herkenhoff'
}

\section{Quarentena blues ou pensamentos pandêmicos - 0 que me/nos/vos motiva?}

Blues quarantine or pandemic thoughts - what motivates me / us / you?

Quarantaine du blues ou pensées pandémiques - qu'est-ce quime/ nous/vous motive? 


\title{
Resumo
}

Esses pensamentos soltos, aforismos, listagens, pequenos devaneios, reflexões, abecedário incompleto, textos foram elaborados durante a quarentena do coronavírus a partir de meados de março de 2020. São aqui apresentados em ordem alfabética, que não corresponde a sua cronologia.

Palavras-chave: Arte e pandemia. Abecedário pandêmico. Devaneios na quarentena. Brasil na quarentena.

\begin{abstract}
These loose thoughts, aphorisms, listings, small daydreams, reflections, incomplete alphabet, texts were elaborated during the coronavirus quarantine from mid-March 2020. They are presented here in alphabetical order, which does not correspond to their chronology.
\end{abstract}

Key-words: Art and pandemic. Pandemic alphabet. Daydreams in the quarantine. Brazil in quarantine.

\section{Résumé:}

Ces pensées lâches, aphorismes, listages, petites rêveries, réflexions, alphabet incomplet, textes ont été élaborés lors de la quarantaine du coronavirus à partir de mi-mars 2020 . Ils sont présentés ici par ordre alphabétique, ce qui ne correspond pas à leur chronologie.

Mots clés: Art et pandémie. Alphabet pandémique. Rêves éveillées en quarantaine. Le Brésil en quarantaine.

\footnotetext{
$1 \quad$ Curador, crítico e historiador da arte brasileiro; foi diretor do MAR/Rio; foi diretor do Museu de Belas Artes do Rio de Janeiro (2003-2006); Curador Adjunto no departamento de pintura e escultura do Museu de Arte Moderna de Nova York, o MoMA (1999-2002), Curador Geral da XXIV Bienal de São Paulo (1997 e 1999); Curador da Fundação Eva Klabin Rapaport. foi Consultor da Coleção Cisneros (Caracas, Venezuela); consultor da IX Documenta Kassel, na Alemanha (1991), foi curador chefe do Museu de Arte moderna do Rio de Janeiro, o MAM (1985-1999).
} 
I

Esses pensamentos soltos, aforismos, listagens, pequenos devaneios, reflexões, abecedário incompleto, textos foram elaborados durante a quarentena do coronavírus a partir de meados de março de 2020. São aqui apresentados em ordem alfabética, que não corresponde a sua cronologia.

Aforismo 1

Se a arte cura, só a arte nos liberta da quarentena.

Em tempo: não há cura alguma sem pão.

II

Devaneioszinhos (I).

Hoje, dia 17 de abril de 2020, não quero nada com o imaginário urbano de Hopper. Durante o dia, só penso no canto do galo garnisé no quintal de minha mãe, na Dança de Matisse, em Água Viva de Clarice Lispector, nos Parangolés de Oiticica, em Fred Astaire na chuva, nos anjos do Fra Angelico, em Elza Soares cantando com as vísceras, em Fernanda Montenegro em qualquer peça, numa conversa calma com Cildo Meireles, n'O Alienista de Machado de Assis, num casal de mestre sala e porta bandeira (qualquer um que seja excelente), num gol do Flamengo no Maracanã, numa apresentação do MC Marechal no MAR, numa fala de Dua Bus囚, na sábia ingenuidade de Volpi, num céu de Sandra Cinto, na poesia de Manuel de Barros, na igreja de São Francisco de Assis do Aleijadinho em Ouro Preto com seu teto do Mestre Ataíde, na escada de Niemeyer no Itamaraty, num prato de alface com tomate como meu jardim de delícias, na raspa torrada do angu, num pastel de feira em São Paulo, num acarajé no pelourinho, no tacacá em frente ao colégio Nazaré no finalzinho da tarde, no sol poente no Arpoador, e, sempre, no sol da Ressureição de Grünewald em Isenheim, e, quando a noite vai chegando, fico muito inquieto... Já exausto de prazeres, não vejo a hora de começar o panelaço.

Amanhã será tudo diferente... pensarei em outros amigos, outras memórias, obras de arte, músicas, filmes, peças de teatro, textos, mas antes de tudo desfrutarei de uma laranja lima, e, quando a noite for chegando, ficarei muito inquieto... Não verei a hora de começar o panelaço.

Depois de amanhã será exatamente como amanhã. Incansavelmente exausto de prazeres. Minha panela é de bom aço.

III

Abecedário (A)

A de Água viva. "É uma tal aleluia. Aleluia, grito eu, aleluia que se funde com o mais escuro uivo humano da dor de separação, mas é grito de felicidade diabólica. Porque ninguém me prende mais." A palavra liberta em plena peste.

IV

Abecedário (B)

B de belo. 
B de bolso... To be or not to be. A dúvida dilemática na pandemia: O bolso ou a vida?... Hamlet é agora um assaltante em Brasília.

\section{$\mathrm{V}$}

Sobre o envelhecer.

Envelhecer é registrar no inventário de perdas afetivas. O coronavírus já está me acelerando esta contabilidade. Triste fim. A ninguém enterrarei.

VI

Calendário.

A arte brasileira nos últimos dois anos desenvolveu duas linhas de trabalho crítico. A primeira, surgiu a 1ํ. de janeiro de 2019; e a segunda, com a Covid 19.

"Vai passar" é a mensagem otimista da bandeira de Marcos Chaves desfraldada no MAR em 2019. Na outra face, só um "?", um aflitivo sinal de interrogação - é a mensagem cética a contrapelo do artista. Para Mário Pedrosa a arte é uma rara força que tem poder contra a entropia social do mundo. O horizonte temporal da Primeira Peste é que "não há bem que sempre dure nem mal que nunca acabe". Vai passar. No dia 31 de dezembro de 2022 é o horizonte promissor no calendário da Primeira Peste. Oxalá seja o fim! A Segunda Peste pode acabar antes. Oxalá acabe!

VII

Aforismo 2 ( $d$ 'après Pedrosa)

A arte é o exercício experimental da liberdade contra a gestão genocida da crise do coronavírus pelo Grã-Tosco Federal, de seu ódio à cultura e de suas tentativas de coibir as liberdades civis.

Lista.

A arte das diferenças, da diversidade.

A arte dos afro-descendentes. Sua base é a impossibilidade de esquecer, a necessidade de lembrar e de construir memória e história,

A arte das populações indígenas em busca de harmonizar tradições identitárias a novos meios de expressão.

A arte das mulheres.

A arte das opções de gênero.

A arte dos diagramas de alteridade.

A arte conceitual do Rio Grande do Sul.

A arte da violentação da violência.

A proliferação geográfica da arte. Contra a hegemonia paulistana, uspiana, sobre a sociedade e a arte brasileira.

A arte das agendas de resistência - Foucault, Agamben, Paulo Freire,

O novo conceitualismo.

A quarta geração construtiva não faz o revival formalista da abstração geométrica, nem certa "pintura protocolar' (expressão de Fernando Lindote), mas aguça o viés político e filosófico do pensamento matemático.

Alguém disse há algumas décadas que a linguagem do vídeo esperava por seu 
Turner. E a web arte, espera por quem? Talvez por seu Cildo Meireles, com sua noção de circuitos ideológicos e de circuitos antropológicos.

VIII

Abecedário (C)

[Parágrafo adaptado de um ensaio sobre a obra de Sandra Cinto escrito durante a quarentena].

C de Cinto (Sandra), C de cinctus da etimologia latina do Nome (cingere), C de cintar os arcos celestiais em pinturas, $C$ de luciluz cintiana arte, $C$ de cintilação estelar impregnando olhares de afetos, $\mathrm{C}$ de centelhas cósmicas tremeluzentes, $\mathrm{C}$ de cintilo de pedrarias de flamejantes estrelas brancas, $C$ das scintillae (para Jung, a alquimia lhe oferecia a ideia das scintillae, das centelhas, que aparecem como ilusões visuais na substância de transformação"), C de cinta musical pentagramática, C de cintura como junção dos corpos celestes pela luz, C de cinturão galáxico da Via Láctea - lá onde estamos como corpos e lá estamos como parnaso de Bilac. $C$ dos céus pintados pela artista, enfim.

Credinho sobre a escrita sobre a arte.

Colocar-se em disponibilidade fenomenológica para o objeto de arte - como ele me vê, o que ele solicita de minha escrita? Voltar - de fato - ao objeto mesmo (Husserl). Compreender humildemente o chavão de que uma imagem vale mais que cem palavras. Buscar a justeza entre palavras e imagem visual (Ostrower). Vá sempre ao dicionário para capturar sentidos das palavras, entender seu significado e origem, seus sinônimos e ideias correlatas, vocábulos mais precisos para expressar ideias. Evitar lugares comuns e rebaixar o peso dos conceitos na moda. Buscar compreender ou dimensionar o universo estético de cada artista, singularizar a análise de cada artista na busca de sua especificidade. Para começar, arte é linguagem (símbolo e signo, semiologia e semiótica, semântica, etimologia e fonética, modos de expressão e de figurar alegorias, sinédoque, metáforas, e até mesmo analogias + etc.). A coragem de se embater com suas discordâncias conceituais. É melhor correr riscos de intepretação do que chover no molhado do lado seguro dos olhares. Evitar ser parte do serviço de marketagem do mercado (mesmo sabendo que o mercado sempre se apropriará de seu texto se ele agrega valor à obra).

Cuidar de sua terminologia, dando preferência à densidade de significado à generalidade de uma significante. Problematizar a fisicalidade do signo material dos meios tradicionais (ler Ralph Mayer) às novas tecnologias. Não há crítica sem história e nem história sem crítica (Argan). Sempre historicizar (Jameson).

Disparadores do imaginário.

Enfrentar suas próprias contradições (isto é difícil) e corrigir abertamente seus erros e omissões na primeira oportunidade.

Devaneiozinhos (I).

Hoje, dia 22 de abril de 2020, evito o imaginário do sol negro de Nerval. Durante o dia, só penso nos balões das Paisagens imaginantes de Guignard, no saque jornada nas estrelas do Bernardo, no Monólogo das Sombras em Eu de Augusto dos Anjos, 
numa gravura de Goeldi com suas casas de olhos apavorados na dita "prevalência da noite moral sobre a física", numa conversa sem fim com o cáustico Miguel Rio Branco com sua má consciência do mundo, numa Sexta-feira da Paixão em Ouro Preto que há de vir, no scorzo na tela Lamentazione sul Cristo morto de Mantegna, escutar o Stabat Mater de Pergolesi, Dies irae do Réquiem de Verdi, as Vier letzte Lieder de Richard Strauss, e, quando a noite vai chegando, fico muito inquieto... Já exausto de prazeres com o mais difícil, não vejo a hora de começar o panelaço.

Amanhã será tudo diferente... pensarei em outros amigos, outras memórias, obras de arte, músicas, filmes, peças de teatro, textos, mas antes de tudo desfrutarei de uma laranja lima, e, quando a noite for chegando, ficarei muito inquieto... Não verei a hora de começar o panelaço.

Depois de amanhã será exatamente como amanhã. Incansavelmente exausto de prazeres. Minha panela é de bom aço.

IX

na alegria das bandeirinhas e das fachadas de Volpi,

no jardim de pedra do templo Ryoan-ji em Kito,

em caminhar por Entrevidas de Anna Maria Maiolino, nos Dzi Croquetes, no rio que passa em nossas vidas na voz do Paulinho da Viola,

em Dom Casmurro de Machado de Assis,

ler uma crônica de Agualusa,

numa batalha de passinho no MAR, numa conversa com Anna Dantes, na poesia de Drummond para o enfrentamento de qualquer pedra na existência, na igreja de São Francisco da Ordem Terceira da Penitência no centro do Rio, na scalinata de Michelangelo na Biblioteca Medicea Laurenziana em Florença, no banquete caipira de minha mãe (galinha ensopada com quiabo e angu), numa faustosa churrascaria no Rio Grande do Sul, no céu de Brasília, numa tarde com Benedito Nunes em sua casa entre flores, ao som ópera e muitas reflexões, e, sempre, nos céu estrelado de Giotto.

$X$

Guerras.

Diante da crescente da ameaça nazista, Matisse, que estava deprimido e desencorajado, escreveu em 1940: "trabalho enquanto aguardo - com uma certa liberdade, sabendo que meus trabalhos já não são esperados." Como os artistas atravessarão a quarentena, sem esperas mas com desafios de criar uma nova ética para a arte.

Durante a invasão de Paris na guerra, Picasso foi visitado pelo embaixador do Führer Otto Abetz, que diante de uma imagem da Guernica, lhe perguntou: "C'est vous qui avez fait cela?". Picasso respondeu: "Non, c'est vous!" A síndrome da Guernica: na guerra entre as guerras, a resistência simbólica.

Durante a Segunda Guerra, a polonesa Katarzyna Kobro queimou suas esculturas de madeira para aquecer seus filhos no inverno. Uma vida vale mais que uma obra prima? Há olhares que dizem que não.

O estado social de guerra contra o coronavírus suscita pensar a linguagem bélica como vocabulário do aparato crítico sobre a arte com termos ou conceitos tais 
como: vanguarda, "ângulo de ataque" (Régis Michel sobre o ponto de vista curatorial), serviço militar (a prática do cubismo para o modernistas brasileiros, conforme Aracy Amaral), embate (entre as posições estéticas antagônicas, sendo Waldemar Cordeiro o mais belicoso dos artistas brasileiros do pós-Guerra), resistência (diz-se da arte que luta contra toda opressão), guerra simbólica, canibalismo (imagem figurada da catequese com a devoração de almas, conforme o jesuíta Antônio Vieira) e antropofagia (em todas as sociedades indígenas de Pindorama que praticavam o canibalismo exógeno de incorporação dos valores do inimigo essa era a base do Manifesto Antropófago de Oswald de Andrade).

Abecedário (D)

D de dúvidas atrozes que me assaltam na quarentena. O que será do mundo que já mudava com a supra-territorialidade digital e que agora se vê vulnerável, fechado em casa? Como se cultivar para a vulnerabilidade? Somos todos seguidores de Gauguin: De onde viemos? O que somos? Para onde vamos? Se estão entediados com a reclusão, por que o tempo me passa tão leve e célere se posso ler, escrever, pensar e estar com a arte? Onde me refugiar em meu silêncio? É possível? Mas, em linguagem geométrica, como viver sem ponto de fuga? Quando veremos a luz no final do túnel? Como evitar me ver na mesma condição dos atacados por uma espécie de claustrofobia interior? Mas antes quem me será arrancado impiedosamente? Quanto horror terei de testemunhar? Será de longe ou de perto? A qual precipício que a Loucura Federal arriscar nos conduzir com seu Arbeit macht frei [und reich] à la III Reich? Como resistir, como enfrentar sua biopolítica, sua necro-política? Como transformar o limite em potência? Como atravessarei esses meses do cachorro louco? Por via das dúvidas, já devo rascunhar uma disposição de última vontade sobre minha biblioteca e minhas peças de arte? Serei contaminado? Sobreviverei? Sim, principalmente se começo por retirar o ponto de interrogação desta sentença.

$\mathrm{XI}$

Properly spelling in quarantine na lingua de Trump.

$\mathrm{J}$ as in jagga jagga

A as in ampidirtuos

I as in ignunt

$\mathbf{R}$ as in raunchsticles

B as in bigoted

$\mathrm{O}$ as in obnoxious

$\mathrm{L}$ as in ludicrous

$\mathrm{S}$ as in scuvley

$\mathrm{O}$ as in outrageous

$\mathbf{N}$ as in nefarious.

A as in ayass

$\mathbf{R}$ as in rut

$\mathrm{O}$ as in obfuscator 
XII

Felicidade quarentenária.

Existe uma alegria na quarentena que não custa nada: encontrar os livros que estavam perdidos na biblioteca bagunçada: os Remarks on colour de Wittgenstein, 0 Água Viva anotado de Clarice, os Escritos e Reflexões sobre arte de Matisse, Number and numbers de Alain Badiou ao qual sempre recorro, um livro de Benveniste que eu não me lembrava mais que tinha; Some Waters de Roni Horn (livro-de-artista que se desdobra em imagens e significados, interminavelmente); os três volumes dos Écrits de Malevitch com o texto sobre o zero suprematista, o extremo da luz; um deliciosa peça gráfica com o texto de Malevitch La paresse comme vérité effective de l'homme, que vou reler para entender se a preguiça é uma boa entrega na quarentena. Um livro me assustou ter chegado pelo correio:

\section{XIII}

Aforismo 3 (d'après Louise Bourgeois)

Se Art is a guarantee of sanity, como proclamou Louise Bourgeois, então ela [a arte] nos livra da loucura da quarentena, das pessoas que não ficam em casa, da irresponsabilidade do Presidente, da devida distância da pessoa objeto do desejo, do beijo dos Amantes de René Magritte, do sol obscuro da melancolia, da ganância de certos comerciantes e de pastores que não dispensam o dízimo - Lamá sabactani? Pai, por que me diminuíste o dízimo?...

\section{Abecedário $(\mathrm{E})$}

E de entropia. De novo Pedrosa. Só a arte pode contra a entropia do mundo pandêmico. Eu acrescentaria... e também os profissionais da saúde.

\section{Abecedário (F)}

É de fascio. Só a prisão decisiva do sócio do Filho, abaixou o fascio do Duce brasiliano. Fascio de feixe de falcatruas federais fodendo a Federação.

\section{Ambrogio Lorenzetti}

Há quase sete séculos está lá na sala mais solene do Palazzo Pubblico de Siena na singular Piazza del Campo - cenário urbano, monumento arquitetônico e arte de tirar o fôlego. Está lá o afresco pintado por Ambrogio Lorenzetti, a Allegoria ed Effetti del Buono e del Cattivo Governo (1297-1310). Mamma mia! Desde primeiro de janeiro de 2019, o Estado brasileiro começou um spietato aggiornamento da Allegoria ed Effetti del Cattivo Governo. Senza fine. Un pagliaccio divertente. Ma molto pericoloso. A squalid President, com seu chinelão de dedo, mas sobretudo com sua envergonhante falta de modos. É preciso que entender que cattivo em italiano ou squalid em inglês não têm o mesmo sentido que em português. $O$ atual cattivo governo instalado no Brasil é demagogia; elogio da tortura; obscurantismo; desmontagem da universidade; diplomacia de fancaria; na expressão chula, tropa familiar de lambe-cu de Trump; ódio às diferenças; a tentativa de destruir a civilização brasileira construída ao longo 
de décadas, de séculos; a destruição da Amazônia; a conivência com a corrupção; o arremedo do nazi-facismo; a misoginia cínica; o racismo indisfarçado; homofobia por denegação; a inveja dos competentes; o arrocho dos mais pobres; o genocídio dos índios e quilombolas; a eficiente administração dos interesses pessoais e familiares; a bancada da bala e das homenagens aos milicianos; os zeros à esquerda; e agora, a pena capital para milhares de brasileiros com a má administração da crise do coronavirus. Mas voltemos às diferenças semânticas entre cattivo e cativo. $O$ povo brasileiro não é cattivo, mas está cativo de um Presidente cattivo. É preciso mais alguma explicação? O mito desalmado é o mico da "pátria amada Brasil".

A peste.

O Covid 19 não é a maior peste no Brasil. Nenhuma excederá a devastadora peste multissecular da chegada dos colonizadores às terras de Pindorama. Nenhuma excederá a devastadora peste multissecular da escravização dos africanos pelos colonizadores e barões do café nas terras de Pindorama. Achille Mbembe trata da necro-política da escravidão colonial. Favelados, indígenas, negros morrem mais que brancos de classes superiores durante a pandemia.

Escuto Mary del Priore falar na rádio sobre história brasileira de pestes. As festas na peste no Rio de Janeiro d'antanho. O Velório (c. 1893), a deliciosa cena festiva porto-riquenha de Francisco Oller.

\author{
Abecedário $(\mathrm{H})$ \\ $\mathrm{H}$ de hora $\mathrm{H}$. \\ $\mathrm{H}$ de História. \\ H de Senhor da Hora dos brasileiros. Qual será seu lugar na História?
}

\title{
Abecedário (I)
}

I de ironia. Ironia, vocábulo derivado do latim ironia, que por sua vez originário do grego eironeia, para "perguntar fingindo não saber a resposta" e ainda para significar disfarce, dissimulação. No começo de março deste ano de 2020 em São Paulo, eu caminhava à noite pela alameda Santos usando máscara e ouvi uma voz em tom sarcástico pelas costas por causa de meu cuidado contra a infecção. Um cara mostrou sua garrafa de cerveja Corona dizendo "olha aqui meu coronavírus" e, em seguida, deu uma baforada de cigarro e concluiu "isso é minha máscara para respirar"! Fina ironia... (bem mais inteligente que o menosprezo presidencial recalcitrante pela "gripezinha"). No dia seguinte, os jornais comunicavam a primeira transmissão comunitária do Covid 19 em São Paulo.

I de inconsciente. Se o inconsciente também se forma na experiência, um crescente inconsciente pandêmico está se incrustando no sujeito durante a crise do coronavírus? Ao lado do inconsciente político (Fredric Jameson, 1992) e, na sequência, do inconsciente gráfico (Rosalind Krauss), o inconsciente matemático (em José Patrício), o inconsciente arquitetônico (em Ascânio MMM), o inconsciente amazônico (em Val Sampaio, Mariano Klautau, Luciana Magno e outros), 
Autorretratos críticos: o que me/nos/vos motiva?

Abecedário (M)

$M$ de motivos. Este seria um autorretrato do crítico e historiador da arte na quarentena? O que me/nos/vos motiva? A ira. A indignação. A solidariedade pelos que morrerão por conta do Mau governo. A afetividade pelas diferenças sociais pelos que mais sofrem na pandemia. A curiosidade pela arte e por novo seu lugar no presente e no futuro.

Acróstico sobre as mortes inevitadas.

G de Bolsonaro

E de Bolsonaro

$\mathrm{N}$ de Bolsonaro

O de Bolsonaro

C de Bolsonaro

Í de Bolsonaro

D de Bolsonaro

I de Bolsonaro

O de Bolsonaro

\section{Abecedário (N)}

N de Não! Quantas vezes direi: "Não!" ao Excelentíssimo Senhor da Hora? Em que língua entenderá ele o Não? Esse homem sem ouvidos para o Outro, que tanto horroriza os países civilizados dos quatro cantos do mundo com sua maneira rude e autoritária, precisa ouvir em mbangala de Angola à slang dos United States o mesmo não indignado: A'a! Ae! Aita! A'loe! Ao! Aowa! Ara! Ayi! Bee ko! Bù! Ei!Ez! Cha! Daabi! Dai tabì! Değil! E kao! Fyn keyn! Hapan! Hayir! Hьит! He! Hi! Hî-î! Hî-î! Hoena! Hyi! laa! Ikke! Indi! Ínín! Inte! Jab! Jo! Ĵok! Không! Lae! LE! LOgat! Loh! MA ho bu! Mana! Mba! Méiyǒu! Na! Nəẽ! Nahániri! Nahi! Näj! Nama! Nau! Naw! Ne! Nē! Ně! Nē a! Nee! Nei! Nein! Nej! Nem! Nie! Nié! Niet! Nije! Nit! Non! Now qay! Nu! Öвöл! Ó til! Ovol! Óxu! Ra ra! Sega! Št!! Tak! Te! Tidak! Tsia! Tsis! Voch! Wala! Yaki! Yayai! Yo'g! Yo'g! Yra! Yyy! Xьay! XiaH-XIa! No! Nope! Por!que no te callas? Excelentíssimo Senhor da Hora!...

\section{Abecedário (O)}

O de Oxalá. Que Oxalá nos proteja contra o falso Messias e seus homens federais, estaduais e municipais dos tempos do 666 do livro do Apocalipse!

O de oxalá tudo melhore! Vai melhorar!

O de ôxente! Interjeição usada para manifestar admiração, surpresa ou mesmo estranheza, e. g., "ôxente! Quando vão amarrar este ogro raivoso?!"

O de oxigênio. Se a sociedade permitisse, o Grande Ladrão de Oxigênio e seus três Los comparsitas sufocariam a ordem constitucional, o Supremo Tribunal Federal, o Congresso, a imprensa livre, todo o arco da educação da pré-escola à universidade, a oposição legislativa, a ciência, as mulheres, os índios, os ecologistas, a sociedade civil indomada. 
O de oxímoro. Um oxímoro é preparar o futuro de uma país com oxiopia míope.

O de Ogum. Que São Ogum Jorge nos proteja da bancada da bala e da direita armada!

O de Oxóssi. Que Oxóssi salve a Amazônia!

O de Oxum. Que Oxum nos resguarde da misoginia que dirige o país!

O de Oxumaré. Que Oxumaré nos ampare na renovação da vida e do lugar da arte!

Nada mais chato...

Nada mais chato do que a chamada telefônica no meio do desenvolvimento de um pensamento complexo no texto, ... não encontrar o livro que você pensa para fechar um argumento, ... ter que ir ao banco em tempos da peste, ... os gifs engraçadinhos matutinos, ... o barulho do vizinho do andar de cima fazendo ginástica; ... Nada mais chato do que qualquer vitimismo em qualquer época. A quarentena é um tempo supressivo da pressão das obrigações prementes, alargamento do tempo, mergulho interior. Nada melhor do que um zap de alguém que nos diz que está bem em tempo de quarentena.

Poliglota reaprendendo a soletrar segredos multilinguísticos, depois da lição de Proper spelling

$\mathrm{J}$ de jallaad (जल्लाद)

A de ajñānī (अज्ञानी)

I de injong chabyeol (인종 차별)

$\mathrm{R}$ de revnivyy (ревнивый)

B de böö

O de oppimaton

$\mathrm{L}$ de ludobójczy

$\mathrm{S}$ de saee $m$ hkan

O de oporojukáva

$\mathrm{N}$ de netolerantní

A de ahli Obsikaris

$\mathrm{R}$ de rasis

O de onye isi ike

Cogitam Deleuze e Guattari em Mille Plateaux (Capitalisme et schizophrénie 2) o nome próprio é um campo de intensidade e a apreensão instantânea de uma multiplicidade. Agregaríamos, inclusive intensidade do Mal e multiplicidade das ações perversas. O desafio é como substanciar um nome para deslindarmos a constituição visceral do sujeito histórico, de um necro-político genocida; ou como compreender tal homo politicus como o Boi abatido por um cutelo de Rembrandt com as entranhas do Mal.

Abecedário $(P)$

$\mathrm{P}$ de peste. $\mathrm{P}$ de Piccola poranduba de pestes e pandemias.

O filósofo renascentista Michel de Montaigne em seus Ensaios escreveu sobre 
os mais diversos assuntos, como a flatulência, os livros, o canibalismo. Sua herdade possuía um castelo e sua torre - nela, Montaigne tinha sua biblioteca, seu estúdio e um quarto para descansar. Era prefeito de Bordéus, mas quando surgiu a peste de 1585, o filósofo estava ausente da cidade. Nunca mais voltou a Bordéus para passar o governo que terminaria em dois meses. Ficou recluso em seu castelo de ideias.

Nem todas as pestes matam presidentes das Repúblicas pelo mundo, como a gripe asiática que matou Rodrigues Alves no Brasil.

A peste da Aids me remeteu a beija-flores, não daqueles que aparecem nas janelas dos artistas que estão em quarentena na pandemia de coronavírus. São os dois beija-flores dos anos 80 levados pela Aids ('"A nossa música nunca mais tocou..."): Cazuza e Leonilson. Dois aristas que desprezaram sobrenome pois só tinham o codinome beija-flor. Apresentaram-se de peito nu, assumiram sua homoafetividade e, a partir dela, trataram da subjetividade de toda uma geração dos "maiores abandonados". Cazuza o pintor de "Num trem pras estrelas / Depois dos navios negreiros / Outras correntezas" (da tela Um trem para as estrelas) e Leonilson o cantor e letrista de O ilha e de o que você desejar, o que você quiser, eu estou aqui, pronto para servi-lo.

O Covid 19 não é a maior peste no Brasil. Nenhuma excederá a devastadora peste multissecular da chegada dos colonizadores às terras de Pindorama. $\mathrm{P}$ da peste gripal europeia em Marcados para viver de Claudia Andujar.

Abecedário ( $Q$ )

$Q$ de quem? Quis custodiet ipsos custodes? Quem julga os juízes? Quem policia os policiais? Quem porá o guiso no pescoço de Sua Excelência o Gato da Presidência? Que será o primeiro a dizer que este rei está nu?

$\mathrm{Q}$ de quem? Quem matou Marielle? Por que? Quem mandou matar?

\section{Abecedário $(\mathrm{T})$}

T de terrorismo de Estado.

Nada mais aterrorizador do que o terrorismo de Estado às escancaras, desfilando de cavalo na praça dos Três Poderes, descendo a rampa do Planalto. Se a história só se repete como farsa (Marx), aquele que pretenda repetir o Al-5 é uma farsante?

Brincadeira com fogo.

Abri o Aurélio e às cegas coloquei meu dedo numa palavra. Repeti a operação algumas vezes. Eis a ordem cronológica dessas palavras encontradas ao acaso: extermínio / pão-duro / remodelação / lagarto / filar / raptorial / parcha e consolidação.

Minha conclusão dos sentidos da estocástica: o mundo de fato não é bom nem mal, mas meu dedo andou apostando a sorte no pessimismo. Tudo ali ou é da lógica do mal ou, sendo neutro, pode escambar na direção malévola. Preferi abandonar o jogo.

\section{Abecedário (T)}

$X$ de $X$ da questão. Quando teremos o X da questão do coronavírus resolvido? Quando será enfrentado o X da questão do impeachment? Qual é o X da questão da 
arte no novo normal?

$X$ de Xerox. Xerox de Trump. Xerox 04 xerox de 03 xerox de 02 xerox do 0,0 à esquerda.

$\mathrm{X}$ de queridxs, de amigxs, se

Florilégio verbal

Quais as mais belas palavras? Para mim, alcantarillado, palavra espanhola que sai na frente no mundo.

\section{Catarata}

Pendotiba.

Quais mais palavras têm a duração de um átimo? Blitz e Zeit. Só?

E quais alocução fere a alma em sibilações cortantes? Stabat mater

E alguns nomes pessoais ou pseudônimos? Capeto, Antonio Obá, Guerreiro do Divino Amor

E palavras que parecem mais sérias do que parecem? Diaresis,

Alfazema

Quais as palavras mais complicadas, mal constituída em seu imaginário. Em meu vocabulário fonético, Schwierigkeit é uma, me traz uma dificuldade sobre onde situar, Verfassung sempre acham que precisa de remendo,

Aforismo

Fiquemos aquarentenados enquanto a Besta fera nos quer aquartelados.

Abecedário (W)

W de Wein traub, que, em tradução livre do alemão, é vinhas da ira...

Imensidões expressivas nos tempos do Google.

Sovramagnificentissimamente em Dante

Anticonstitucionalissimamente em Rui Barbosa.

Pneumonoultramicroscopicsilicovolcanoconiosis em Medicina.

Rindfleischetikettierungsüberwachungsaufgabenübertragungsgeset na incrível lógica da língua alemã.

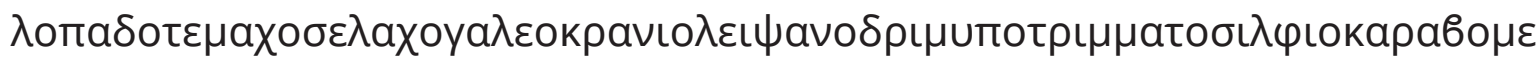

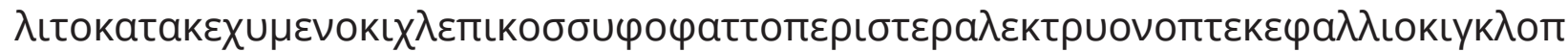

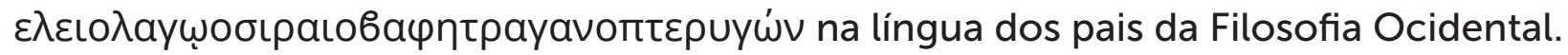

1000000000000000000000000000000000000000000000000000000000 0000000000000000000000000000000000000000000 ou o googol Matemática.

Abecedário (Z)

Zeit. O tempo não para. É célere e lentíssimo na quarentena. Antecipar decisões de isolamento sem a orientação da ciência é semear o vírus em pulmões inocentes. 